\title{
IS TWINNING HEREDITARY?
}

\section{Problem Much More Complicated Than It Appears at First Sight-Two Kinds of Twins-Possible Influence of the Father-The Frequency of Multiple Births}

\author{
C. H. Danforth
}

Department of Anatomy, Washington University Medical School, St. Louis, Mo.

$\mathrm{T}$

HE layman is often impatient with the indefinite character of much of our eugenic information. It is not easy for him to understand the difficulties that attend an investigation into the heredity of what may seem to be a single clear cut characteristic. For this reason it may be of interest to point out a few of the obstacles met in such a study. The question of a possible hereditary tendency for twin production may be selected for this purpose. The problems encountered are not identical with those that would be met in the investigation of the heredity of some other characteristic but they are in a measure similar and will serve to furnish a typical example.

The occasional occurrence of twins among the offspring of man and other animals that usually produce only one offspring at a time, has always been a matter of interest to both the popular and the scientific mind. This interest is due not so much to the fact that these mammals may sometimes produce two or more young at a birth as to the extreme similarity that frequently exists between the young thus produced. The causes that result in twin production, however, are not fully understood, and still less is known of the role heredity plays in this connection.

If one attempts to learn more about the heredity of twinning he is forced to consider a number of subsidiary questions which are in themselves of considerable interest. It is the main purpose of this paper to call attention to the bearing of some of these secondary considerations in relation to the question of an hereditary tendency toward twin production. Incidentally a few fragmentary data from family histories are also presented, but the writer is still collecting this material ${ }^{1}$ and has little hope that it will be in shape for final publication for some time.

\section{THE ORIGIN OF TWINS}

One of the first questions to be raised at the beginning of an investigation into the existence or non-existence of any hereditary tendency is: What is the exact nature of the characteristic in which this tendency is to be sought? It might seem that nothing could present less difficulty in this connection than twinning. But such is far from being the case.

In the first place, it may be recalled, embryologists hold that twins arise in two very different ways. In one case, two separate egg cells, from the same ovary or from opposite ovaries, are fertilized each by a separate sperm cell. The resulting embryos develop independently like the different members of an ordinary litter. They need have no greater resemblance to each other than brothers and sisters born at different times, and the chance that they will be of like sex is the same as for any two consecutive children in the same family. Such twins are variously designated as fraternal, heterologous, biovular. There seems to be amplc evidence that many pairs are of this sort.

In the case of the other class of twins, it is claimed that both members of the pair are derived from a single egg that has been fertilized by a single sperm. At some time subsequent to fertilization two centers of growth appear in the

1 The writer of this paper will welcome family histories in which several pairs of twins occur, or other data bearing on the question of hereditary twinning. 


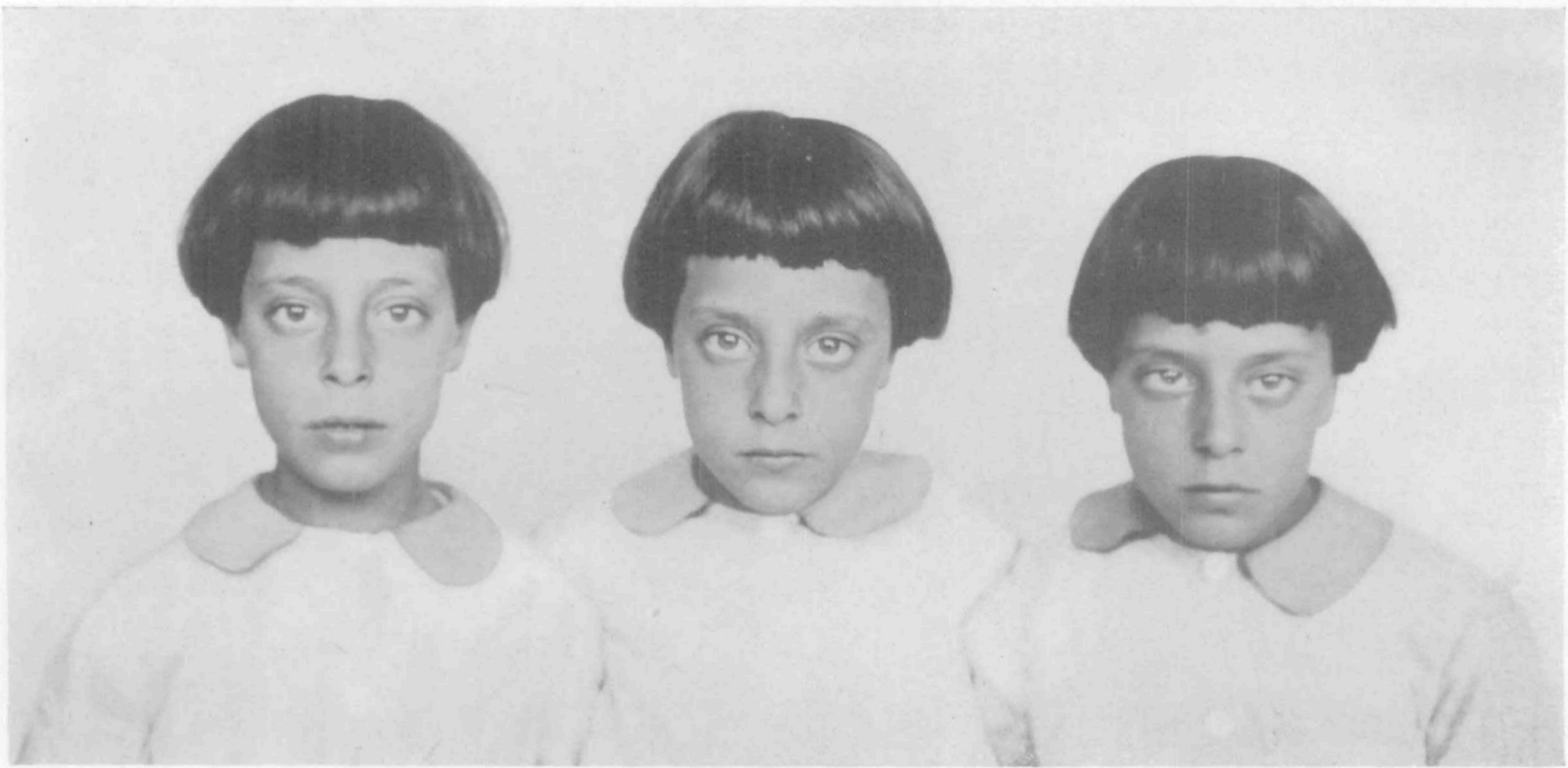

\section{DO THESE GIRLS LOOK ALIKE TO YOU:}

These triplets from St. Louis illustrate one of the difficult problems that confronts the student of hereditary twinning. Triplets, it is believed, may be derived from one, two or three egg cells. In which class do these three girls belong? People who see them for the first time usually consider them very similar. Their eyes, hair and complexions are practically indistinguishable to ordinary observation. They are the youngest of thirteen children, and their hair is darker than that of any of their brothers or sisters. Yet it will be seen that their features are by no means identical, although more similar than one would expect if they really represent three distinct ova. The doctor who attended their birth says they had each a complete and scparate set of foetal membranes. There are no other cases of twins or triplets known in this family, or among the immediate relatives in Germany. (Fig. 1.) 
embryonic cell-mass and from each of these centers a distinct individual develops. Such twins, known as identical, homologous, or uniouular, are always of the same sex and, moreover, often show the most striking similarity. ${ }^{2}$ The evidence in favor of the existence of this type of twins is drawn from many sources and seems quite conclusive. ${ }^{3}$

It will be apparent from the foregoing that there are at least two fundamentally different classes of twins which must be taken into account in a study of heredity. Biovular twins, since they orve their existence to the simultaneous ovulation of two ova instead of one, must be explained entirely by reference to some attribute of the mother and could not possibly be due to any characteristic of the father. Uniovular twins, on the other hand, might conceivably be due to factors supplied by either the father or the mother or, like a recessive character, to some inherent peculiarity in the germ cells of both parents. In one case the characteristic is manifested in the parental generation (mother), in the other it appears in the filial generation (twins themselves). This is an obvious and important distinction. Indeed it might be argued that the occurrence of uniovular and biovular twins represents two entirely distinct and unrelated phenomena. Yet this point is frequently neglected in studying twins from a statistical or hereditary standpoint.

Simon Newcomb's memoir" "A statistical Inquiry into the Probability of Causes of the Production of Sex in Human Offspring," may be mentioned as one illustration of such an oversight. In this article it is shown from very extensive data that twins are of the same sex much more frequently than can be explained by reference to the laws of chance. Even so careful a student as Professor Newcomb, proceeding from this fact and completely ignoring the possibility of the existence of these two types of twins, tried to prove that the sex of twins, and therefore all embryos, is determined subsequent to fertilization. If, however, the current views as outlines above are correct it follows that, while the data presented by Newcomb are exactly what would be expected, his arguments from them are practically pointless.

\section{THE TWO KINDS OF TWINS}

Since embryologists insist that students of heredity recognize the existence of these two classes of twins, the next question that arises is as to how they may be distinguished. It is commonly assumed that twins of opposite sex are necessarily biovular, while those of similar sex may belong in either class. It therefore becomes a question of passing judgment on the degree of resemblance between the members of each pair where the sex is the samc. This is no easy matter. On the one hand biovular twins may sometimes closely resemble each other as is shown by the fact that two brothers or sisters born several years apart are frequently very similar. That uniovular twins, on the other hand, may be very different is strikingly indicated by those cases in which one of the individuals has suffered from some handicap before birth, or is reduced to a mere parasite attached to its more vigorous partner. Identity is rarely attained.

The relation of the foetal membranes in which the twins develop has been proposed as a criterion, and it is probably true that any pair of twins which at birth are found to be surrounded by a single set of membranes have come from a single ovum. But it does not necessarily follow that those surrounded by separate sets of membranes are biovular. ${ }^{5}$ That they frequently are not

2 The extent of this similarity, which may reach even to the finger prints, has been studied by Professor Wilder and others: see H. H. Wilder in the American Journal of A natomy, vol. i.

The following observations may be mentioned: (a) in some lower forms it is possible experimentally to cause two embryos to develop from one egg; (b) in the case of the North American Armadillo, it is definitely established that four young regularly develop from each egg; (c) embryos showing all grades of division from a slight bifurcation to complete separation of individuals are actually found.

1 Carnegie Institute of Washington Publication No. 33.

S This is the present view of Sobotta and others, but such data as are referred to in the text seem to throw some doubt upon it. 


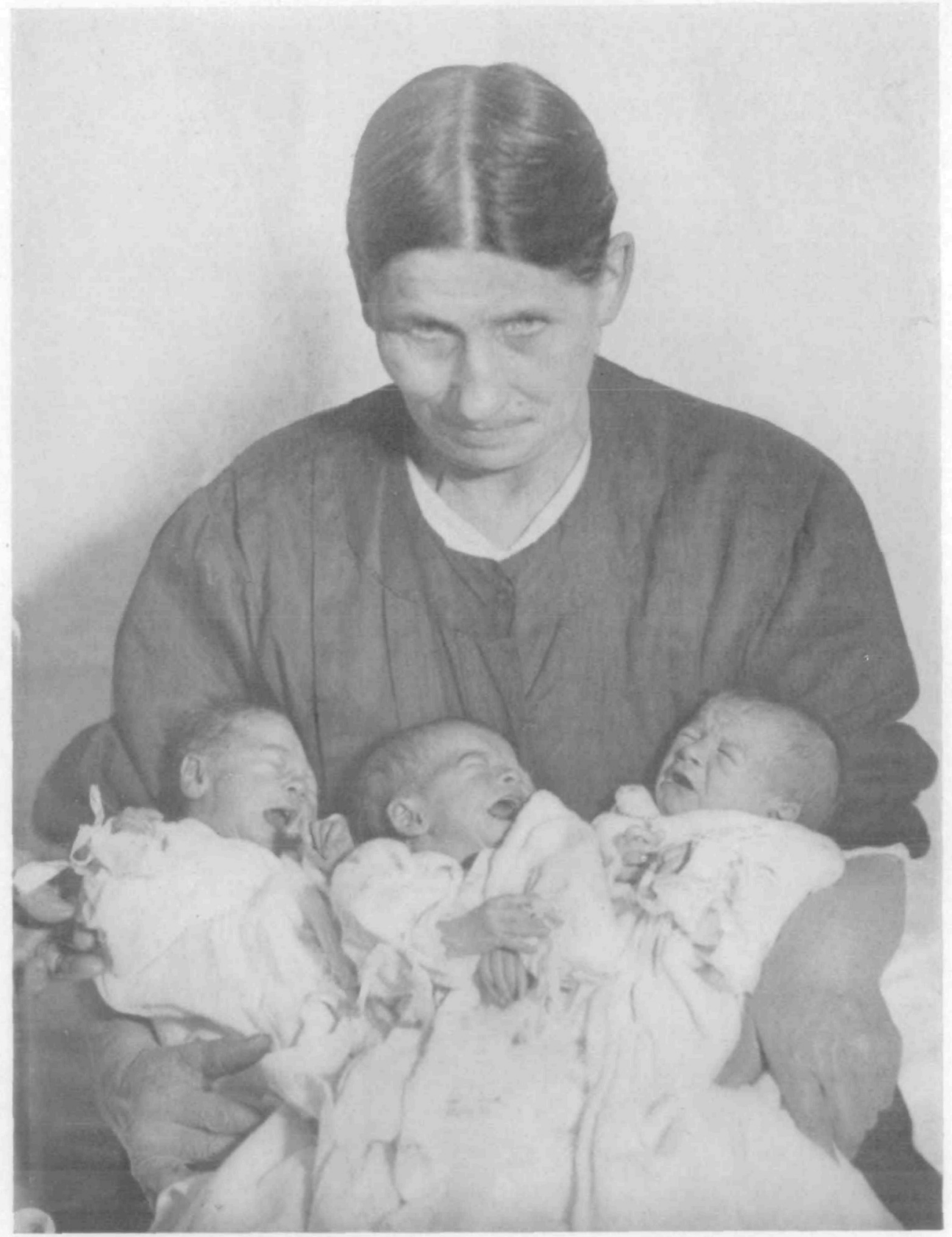

PLURAL BIRTHS ARE NOT AN UNMIXED BLESSING

"The stork is one bird that does not go South with the millionaires in winter, but remains up North conscientiously on the job," says Charles Hopper, of 1620 Race Street, Cincinnati, Ohio. Thus Hopper, in announcing the birth of triplets, announces at the same time a cheerful outlook on life. His three latest daughters, who were just a week old when the photograph was taken, are here shown in the arms of their grandmother, Mrs. Elizabeth Koch. The Hopper home is no strange place to the stork, who has made seven previous visits. This is the first time he has ever been so generous in any one call, however, all of the other children having been born singly. Photograph from Paul Thompson. (Fig. 2.) 
so is suggested by the followingr, reasoning.

It is found, for example, that of 37,621 pairs of twins born in Germany and France, there were 13,315 cases in which one twin was a boy, the other a girl. Now an interpretation that may be put on such data is this: These 13,315 cases represent half of the biovular twins-since such twins have equal chances of being of the same or of opposite sex. This means that of the whole number roughly 26,630 cases represent biovular twins and the remaining 10,991 cases represent uniovular twins, from which it appears that $29+$ $\%$ of all twin cases are uniovular. ${ }^{7}$ The textbooks of obstetrics published in Germany and France, basing their statement on the relations of foetal membranes, generally give the number of uniovular twins as about $15 \%$. Here is a discrepancy that seems to have been generally overlooked, but it is very probable that the difference between $1.5 \%$ and $29 \%$ represents the number of cases in which uniovular twins develop in separate sets of foetal membranes.

\section{POSSIBILITY OF OTHER KINDS}

There is another point that cannot well be overlooked in this connection. Prof. Thorndike ${ }^{8}$ found that when the degree of similarity between the two members of different pairs of twins is measured and plotted for a large number of cases the resulting curve is smooth and not two-humped as might have been expected. The mode falls at a point higher than that for comparisons bctween ordinary brothers and sisters, but considerably below the point representing identity. If twins fall only into the two classes usually postulated it is difficult to see how such a result could be obtained. Similar study of other, and if possible, more extensive material is greatly needed.

It may ultimately be possible to show that Thorndike's smooth curve repre- sents the leveling effect of like environment reacting on biovular twins and of somatic variation affecting uniovular twins, but it may also be that the two types mentioned do not represent all the classes of twins, for it must be admitted that theoretically there are other possibilities. One such possibility is suggested by the work of Boveri $i^{9}$ and others on the eggs of bees and sea-urchins. It was found by these investigators that the entrance of the sperm to the egg occasionally stimulates a precocious division of the latter so that the sperm nucleus is able to unite with only one half of the original egg nucleus, leaving the other half to develop (in these lower forms) parthenogenetically. If such a condition were to arise in man, the second half of the egg nucleus might, so far as is known, be fertilized by one of the innumerable superfluous sperm cells, in which case we would perhaps get a pair of twins derived from one egg and two sperms. Such three-germ twins might even be of opposite sex, yet they should be more similar than ordinary brothers and sisters. The at present puzaling distribution of twins in certain families could be explained very well on this assumption, but such a postulate lacks proof, and one must proceed cautiously in introducing new hypotheses.

\section{FREQUENCY OF TWINS}

For the student of heredity it is always desirable to know the "normal incidence" of the character under investigation. Knowing this it is possible to calculate, on the assumption that the characteristic appears fortuitously, the probability that it will be found once, twice or oftener in groups of a given size. With this information at hand one may then determine whether the characteristic regularly appears in certain families enough oftener than the laws of chance would explain to warrant regarding it as hereditary.

The approximate incidence of twin births as a whole is easily obtained.

- Simon Newcomb, op. cit.

1 Miss Margaret $V$. Cobb has recently applied the same reasoning to American data with similar results. Science, N. S., Vol. XLI, So. 1057, pp. 501, 502. April 2, 1915.

B Archives of Philosophy, Psychology and Scientific Methods, No. 1, 1905.

- This work is scattered through numerous journals dealing with experimental embryology, etc. 


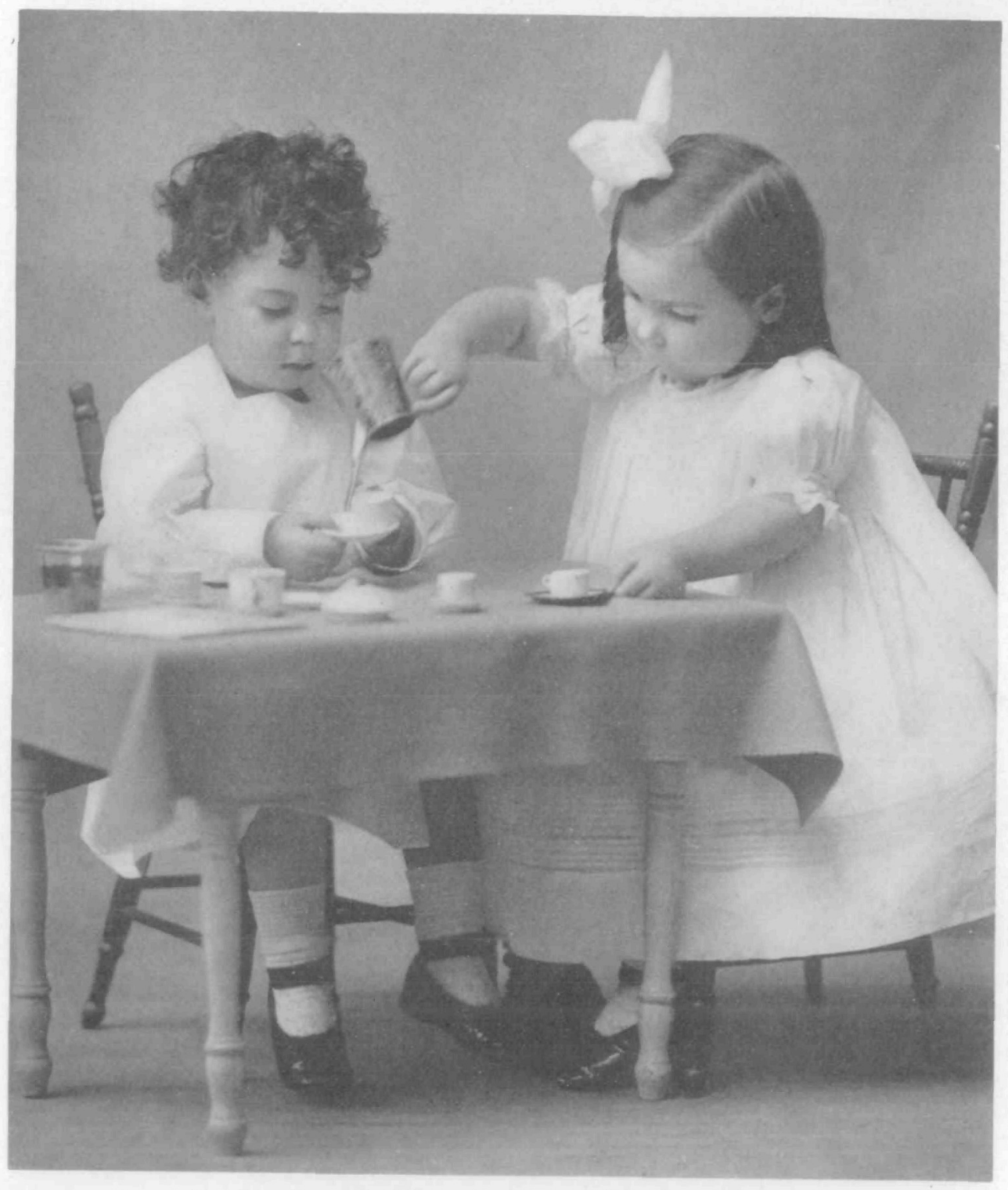

TWINS FROM TWO DISTINCT EGG CELLS

As they are of different sexes, it is probable that they are not from the same egg cell; and the difference in their appearance, at first sight, is considerable. But closer examination shows that the hair is the only visible feature in which they differ widely. Photograph from The Nursery Studio, Washington, D. C. (Fig. 3.)

For example, it is stated ${ }^{10}$ that in Prussia one birth in eighty-nine results in twins; in Naples, one in 158; in Russia, one in thirty-two, etc. In certain provinces of China twins are said to be almost unknown. Of the 75,030 births recorded in St. Louis during the five years from February, 1910, to February, 1915, 828 are reported as twins or triplets. This indicates that the incidence of multiple births here is about one to 90.6 . Of course these figures tell nothing of the relative frequency of the different classes

${ }^{10}$ Textbooks of obstetrics, etc. The Prussian statistics are said to be based on $13,000,000$ births, the Russian on $6,000,000$. 




FROM ONE OR TWO EGG CELLS?

The most obvious difference between these twins is that one drinks faster than the other. In features the resemblance is close. Yet no one can say from mere inspection whether they represent the twinning that is due to the fertilization of two egg cells, or the twinning that is due to a single egg cell splitting in halves; and as the two kinds of twirning are very likely inherited in a different manner, the study of the problem is made difficult. Photograph from the Nursery Studio, Washington, D. C. (Fig. 4.)

of twins, a decided handicap for the student of heredity.

\section{THE HEREDITARY TENDENCY}

The kind of evidence that one gets as to the heredity of twinning may be indicated by reference to a group of fifty St. Louis families. The investigator had no knowledge of any of these families until in each case, the birth of twins was reported to the bureau of vital statistics. On looking into the family histories, it was learned that these fifty new-born pairs of twins had 171 older brothers and sisters born singly and twenty (ten pairs) who were twins. The frequency of twins among the brothers and sisters of twins then is about 1:18. In the mothers' fraternities there had been 318 single births and ten pairs of twins (1:32), and in the fathers', 219 single and eight pairs of twins (1:37). Comparing these figures with the "normal incidence" for St. Louis $(1: 90.6)$ one is justified, especially since essentially similar figures are obtained from more extensive data, in concluding that twin production is frequently a family peculiarity.

Analyzing the individual families, evidence is found that what seems to be biovular twinning is hereditary in the direct female line. The tendency to uniovular twinning likewise seems to be transmitted through the female and, since the incidence of twins is higher than normal in the fraternities of the fathers of twins, ${ }^{11}$ it is probable that it may also be transmitted through the male. Whether there is any relation at all between the two types is an open question.

While some of these families furnish beautiful charts indicative of an hered-

11 There is indication that this is also the case with Shropshire sheep. See Rietz and Roberts, Journal of Agricullural Research, September, 1915. 
itary tendency for twinning, others are frequently met with in which, while there may be a record of many indidivuals in several generations, only one pair of twins appears. In these instances the twins sometimes seem to be biovular, sometimes uniovular. Such family histories may indicate that while twinning is in some way hereditary in most instances, it may nevertheless at times appear sporadically. The most probable inference to be drawn from this fact would seem to be that the ability to produce twins is possibly common to all strains and that the frequency of twin births in different lines is merely relative. It is not likely, on the one hand, that strains will be found in which twins never occur nor, on the other hand, in which there is nothing but twins. But that such causes as may tend toward twin production ${ }^{12}$ are more constant or react more effectually in some lines than in others seems evident. That one of the factors commonly involved in the case of both uniovular and biovular twinning is hereditary seems to be well established, although it cannot as yet be stated whether or not the method of transmission is Mendelian.

\section{SOLUTION NOT IMPOSSIBLE}

In the foregoing discussion an attempt is made to give the "setting" of a concrete problem in the study of human heredity for which purpose the question of twinning is selected. The obstacles that are met in attempting to solve this problem are found to be of such a nature as to prevent a quick arrival at final conclusions, but they are not such as to discourage the hope that a definite solution of the problem may be obtained. Before such a solution is reached, however, a number of incidental, and perhaps unforeseen, questions must be disposed of. These questions often call for excursions into somewhat remote fields of investigation, but this fact instead of detracting from the interest of the study or the urgency for its prosecution, adds materially to both. It is only through the careful evaluation and correlation of all these contributary data that entirely satisfactory conclusions can be hoped for.

12 There is not space to discuss these causes in detail. Many obstetricians consider age an important influencing factor (biovular twins). A slight transient hyper-acidity of the uterine fluids has been suggested as a factor favoring the production of uniovular twins.

\section{Laws to Restrict Miscegenation}

Twenty-eight states have laws or constitutional provisions forbidding the intermarriage of negroes and white persons, while twenty States have no laws on the subject, according to Albert Ernest Jenks, who reviews the legislation in the American Journal of Sociology (March, 1916). In ten States, bills introduced in the legislatures and aimed at forbidding negro and white marriages were defeated in 1913, largely through the activity of the National Association for the Advancement of Colored People. This association announces that it does not favor intermarriage, but objects to such legislation on the ground that it is ineffective and discriminatory, that it leads to the degradation of negro women, and "for the physical reason that to prohibit such intermarriage would be publicly to acknowledge that black blood is a physical taint, something no self-respecting colored man and woman can be asked to admit." Prof. Jenks points out that in the States which have laws, these laws differ widely in the interpretation placed on the word "negro." "If effectual legal barriers against negro-white amalgamation are desirable," he concludes, "they should perfectly agree as to the legal and racial status of the so-called 'negro,' and miscegenation of every form and every instance between negro and white persons must be made a felony in every American State." 